\title{
Artifactualization without Physical Modification
}

\author{
Tim Juvshik
}

\author{
tjuvshik@umass.edu
}

Penultimate Draft - Please Cite Published Version (Res Philosophica, forthcoming)

Abstract. Much recent discussion has focused on the nature of artifacts, particularly on whether they have essences. While it's often held that artifacts are intention-dependent and necessarily have functions, it's equally held, though far less discussed, that artifacts are the result of physical modification of some material objects. This paper argues that the physical modification condition on artifacts is false. First, it formulates the physical modification condition perspicuously for the first time. Second, it offers counterexamples to this condition. Third, it considers, and rejects, two responses to these counterexamples, one which appeals to the distinction between being a $K$ and being used as a $K$ and another which argues that the counterexamples are merely of functional, not artifactual, kinds. Finally, it considers, and rejects, a more general objection that appropriation makes artifact creation too easy. Therefore, artifacts can be created by appropriation and it sketches some success conditions for such appropriation.

\section{Introduction}

Philosophical interest in artifacts - things like chairs, wine bottles, lampshades, and pacemakers - is on the rise. Special attention has been paid to whether artifacts have essences (i.e. whether there's anything essential to being an artifact or a member of a particular artifact kind). In other words, many philosophers are asking, what makes something an artifact? We all have a pre-theoretical grasp on what artifacts are: they are things made by humans, usually to fulfill some goal or purpose. Despite our easy familiarity with artifacts in our everyday life and the rise in attention that this question has recently received, an account of artifact essences has remained elusive.

There are a number of plausible pre-theoretical features of artifacts that appear to be borne out by our artifact practices. Since artifacts are things made by humans, they at least seem to be intention-dependent. That is, artifacts are things agents make intentionally. Moreover, artifacts seem to be intentionally made to serve some purpose or fulfill some function. For example, a carpenter intends to make a chair and the thing she makes is intended to serve a given purpose, namely seat a single individual. These two pre-theoretical features seem like a plausible package for artifact essences and indeed, they've both received substantial theoretical support. ${ }^{1}$ However, just intending to make

\footnotetext{
${ }^{1}$ For discussion of intention-dependence see Hilpinen 1992, Dipert 1993, Bloom 1996, Baker 2007, Levinson 2007, Thomasson 2003, 2007, 2014, Mag Uidhir 2013, Evnine 2016, Khalidi 2016, Goodman 2020, and Juvshik 2021a. For discussion of artifact function see Kornblith 1980, 2007, Houkes and Vermaas 2004, Scheele 2006, Elder 2007, 2014, Grandy 2007, Soavi 2009, Hughes 2009, Preston 2009, Franssen and Kroes 2014, Evnine 2016, Olivero 2019, Bahr 2019, and Juvshik 2021b. For an overview of artifact essences see Koslicki 2018, ch. 8.
} 
something to serve some function doesn't seem sufficient for successfully making an artifact. Imagine I intend to make a bowl to serve salad. If I don't do anything to execute my intention to make something to serve salad, then I won't succeed in making a bowl. As a result, intention-dependence and function seem necessary, but not sufficient, to make an artifact. What further condition could be added to yield jointly necessary and sufficient conditions for being an artifact?

A further plausible pre-theoretical condition on being an artifact is that they must result from the physical modification of some material things or stuff. To make a salad bowl or a chair, an agent does something - she shapes, fires, and glazes some clay or she cuts, sands, nails, and varnishes some wood. This physical modification condition seems to be borne out by our artifact practices. Shirts result from cotton being dyed, shaped, and sewed. A cake is made by mixing a variety of ingredients and subjecting them to heat. Buildings are complex, technical creations constructed out of diverse materials by multiple coordinating agents. Chairs, pencils, cars, key fobs, cellphones, boots - almost everything that surrounds us in our daily lives - appear to be the result of agents intentionally physically modifying some objects in order to serve some function or purpose. While this physical modification condition is pre-theoretic, many philosophers also hold this view. ${ }^{2}$ Despite being intuitive and widespread, no one has given a full defense of the view that artifacts must be the result of physical modification, let alone formulated the condition precisely. Moreover, it may seem subject to easy counterexamples. It's therefore important to see why and how it fails. Thus, my aim in this paper is to show that the physical modification condition on artifacts, or PMC for short, is false. As a result, artifacts can be created by appropriation - pre-existing objects can become artifacts without being physically modified. ${ }^{3}$ I also aim to accomplish two other ancillary goals: first, to explicitly formulate PMC for the first time, and second, to sketch some conditions for successful appropriation in order to show that there are some constraints on agents's intentions when appropriating objects as artifacts.

The paper is structured as follows. In section $2 \mathrm{I}$ consider successive formulations of PMC in order to capture its strongest version. In sections 3 and 4 I consider various concrete and abstract counterexamples to PMC: first that it excludes cases of unmodified objects that are intuitively artifacts, such as a piece of driftwood that's moved from the beach to my kitchen to be a wine rack, and second

\footnotetext{
2 Those that explicitly adopt the physical modification condition include Weitz 1956, Oswalt 1976, Davies 1991, ch. 5, Dipert 1993, 23ff., Mag Uidhir 2013, 99-100, n7, Evnine 2016, 132-133, and Hick 2019, 63n6, while Sankowski 1980, Gaut 2000, Franssen 2006, 43, Elder 2007, 2014, Soavi 2009, Houkes and Vermaas 2014, and Franssen and Kroes 2014 all implicitly adopt it, while Korman's commitments in his 2015, 155-156 aren't entirely clear.

3 Those that accept appropriation include Eaton 1969, Hilpinen 1992, 64-65, McLaughlin 2001, 54, Dickie 2004, 49, Scheele 2006, Thomasson 2007, 2014, Baker 2007, 53n8, Grandy 2007, 28, Evnine 2013, Preston 2013, 96-103, Reydon 2014, 138-139, and Koslicki 2018, 231n14.
} 
that it excludes the possibility of abstract artifacts, such as fictional characters or musical works. In sections 5 and 6 I consider, and reject, two ways of resisting the counterexamples in section 3 , one which appeals to the distinction between being a $K$ and being used as $a K$, and one which argues that the driftwood wine rack is indeed a wine rack, but not an artifact, recently raised by Evnine and Mag Uidhir, respectively. Thus, artifacts can be created by appropriation. In section 7 I consider a general realist worry that appropriation makes creation too easy - we can bring a new entity into existence by our thoughts alone - and I sketch some conditions for successful appropriation in order to show that there are relatively strong constraints on appropriated artifacts. This paper thereby shows that we have good reason to reject the widely held but infrequently formulated physical modification condition on artifacts. Thus, whatever artifacts are and regardless of whether they have essences, they can at least be created by appropriation.

A note on method: the argument of this paper ultimately involves a clash of intuitions about cases. In order to resist the counterexamples I raise, it's not enough to advance competing intuitions; one must also explain why they're not genuine counterexamples. I explore two particularly salient ways in sections 5 and 6 and show why they fail. Since appropriation is compatible with most artifacts being the result of physical modification, it is the more expansive notion and, given the failure of alternative ways of explaining the putative appropriation cases, it's in a better explanatory position than PMC. Finally, for the purposes of this paper I will make two assumptions. First, I will assume that all artifacts have functions, although nothing particularly hangs on this. Second, there's a background metaphysical debate about which I will remain neutral, namely, the monism/pluralism debate about material objects and the relation between an object and its matter. There are three general views on this question: the object is identical to its matter, the object is (partly) constituted by its matter, and that being a particular kind of object such as a scarecrow or a cellphone is a phase sortal of the matter just as a tadpole is a phase in the life of a frog. Each position will constrain some of the details of what one can say about artifacts and appropriation. I will sometimes talk of 'creating' a new artifact by appropriation. Depending on which of the three views one goes for, such creation talk may need to be paraphrased or explained away. For example, the phasalist wouldn't want to say that a new object has been created but rather that some object has gained a new (phasal) property. For the purposes of the present paper such creation talk should be treated as a convenient shorthand, to be cashed out in 
whatever manner one's metaphysical predilections lean. What else I say about appropriation is general enough to be compatible with any of the three principal positions. ${ }^{4}$

\section{Formulating the physical modification condition}

While artifacts have been the focus of much recent discussion, there's very little on their physical modification. Interestingly, the majority of work on this topic is found in the philosophy of art. Debates about the nature of art often start with recognizing that artworks are at least artifacts. ${ }^{5}$ However, in the mid-twentieth century Morris Weitz (1956, 33-34) argued against this artifactuality condition on the basis that art objects don't need to be physically modified, while artifacts do, on the basis that a piece of driftwood could be moved from a beach to an art gallery and thereby become art but not, allegedly, an artifact.

Stephen Davies (1991, 122-3) reconstructs Weitz's argument against the artifact condition on artworks as follows:

(P1) A piece of driftwood can become an artwork without its being modified in any way beyond its removal to an art gallery.

(P2) The piece of driftwood is not artifactualized in the course of its achieving art status

(because it is not worked on).

(C) Therefore, the artifactuality condition fails to hold.

The motivation for (P1) is an appeal to the appreciative practices of the artworld. Since Duchamp's Fountain and other ready-mades, found objects have been accepted as artworks when placed in galleries and displayed in exhibitions. ${ }^{6}$ A piece of driftwood moved to a gallery would plausibly be treated as an artwork, given the current practices of the artworld public.

The motivation for (P2) is more complicated. Weitz says little enough about the argument, so the bracketed part of (P2), "because it is not worked on", is added by Davies. Nevertheless, I think it's uncontroversial what Weitz had in mind. He's assuming that because the driftwood isn't physically modified when it's moved from the beach to a gallery, it hasn't become an artifact. To be an artifact requires physical modification (PMC) and the driftwood, while intentionally placed in a gallery, did not result from any physical modification (except being moved), so is an artwork but not an artifact.

\footnotetext{
${ }^{4}$ One could distinguish between an object becoming an artifact by appropriation and an artifact being created through physical modification. I don't see a relevant difference between these two, but there is debate about what genuine creation involves. If one does accept such a distinction, then the paper should be read as arguing for the former, weaker claim.

5 See Davies 1991, ch. 5, Gaut 2000, Levinson 2007, and Mag Uidhir 2013, ch. 3.

${ }^{6}$ See Evnine 2013 for discussion of the history of Fountain.
} 
However, neither Weitz nor Davies give a robust formulation of PMC. Before assessing PMC, I consider various formulations with the aim of developing the strongest and most plausible version.

First, note that PMC only seems plausible as a necessary condition on artifactuality. As Davies (1991, 131) notes, cutting off your arm artifactualizes neither you nor your arm. Thus, PMC isn't sufficient for artifactuality. ${ }^{7}$ As a first stab, consider the following:

$\mathrm{PMC}_{1}$ : If $x$ is an artifact, then $x$ has undergone some physical modification.

While this generic formulation seems to express the idea behind PMC, it doesn't specify that the modification must be intentional. In keeping with the widely held view that artifacts are intentiondependent, those who adopt PMC have intentional modification in mind. Thus, we should include an explicit reference to intentions:

$\mathrm{PMC}_{2}$ : If $x$ is an artifact, then $x$ is the result of intentional physical modification by some agent(s).

Intentions are always had by some agent, and since some artifacts are the products of multiple agents (skyscrapers, automobiles), the relevant agent can be plural.

The relevant physical modification is to the material used to make the artifact. A lump of clay is moulded to make a statue, rubber is used to make a tire, which in turn is used along with a chassis, engine, carburetor and other artifacts to make a car, pieces of wood are sanded and varnished and nailed together to form a table, and so on. We therefore get the following:

$\mathrm{PMC}_{3}$ : If $x$ is an artifact, then $x$ is the result of intentional physical modification of some preexisting material object(s) by some agent(s).

Following Davies (1991,133), we can call the pre-existing material object(s) that make up the artifact its progenitors. It's an open question what the relationship is between an artifact and its progenitors. As I mentioned at the outset, there are three general positions on this question, that the progenitors are identical to the artifact, that they constitute the artifact but are distinct from it, and that the artifact is a phase sortal of its progenitors. ${ }^{8}$ I will remain neutral on this issue, since PMC only requires that the artifact results from modification to its progenitors, which is compatible with all three positions, though some paraphrasing may be required. ${ }^{9}$

\footnotetext{
${ }^{7}$ See also Iseminger 1973.

${ }^{8}$ Davies (1991, 133), Dipert (1993, 121-125), and Mag Uidhir (2013, 99) all opt for the second option.

${ }^{9}$ My preferred view is that artifacts are phase sortals of material objects, though defending this is beyond the scope of this paper.
} 
While $\mathrm{PMC}_{3}$ seems like a robust characterization of Weitz's view of artifactuality, it doesn't say anything about the kind of modification required. The driftwood did undergo some physical modification - a change in place - but Weitz and others who endorse PMC obviously don't take this to be the relevant kind of physical change. A change in location is only a change in the driftwood's extrinsic properties. To make an artifact in the sense relevant to PMC, there must be a change in the intrinsic properties of the object. ${ }^{10}$ According to Weitz, to make the driftwood into an artifact, an agent would have had to change at least one of its intrinsic properties by, say, sanding it and adding varnish or removing parts of wet wood or whatever. Including the intrinsic condition, we get:

$\mathrm{PMC}_{4}$ : If $x$ is an artifact then $x$ is the result of intentional intrinsic physical modification by some agent(s) of some pre-existing material object(s).

This seems to adequately capture the condition motivating Weitz's second premise in the driftwood argument. The driftwood isn't an artifact because it doesn't meet $\mathrm{PMC}_{4}$ : it merely underwent a change in its extrinsic properties.

$\mathrm{PMC}_{4}$ requires that an artifact results from intrinsic physical modification, but as formulated it might suggest intrinsic modification of the progenitors's monadic properties. However, there are clear cases of artifact creation that result from mere combination of some pre-existing material objects and combination doesn't require change to the progenitors's monadic properties. Consider two such cases:

Coffee table: a table can be made by placing a pane of glass atop an old propeller, where the weight of the glass holds itself in place.

Rock garden: a common ornamental practice is arranging rocks and other objects on your lawn to make a rock garden.

Both cases involve several material objects being rearranged or combined to form a new artifact but without their combination involving change to their intrinsic monadic properties.

The combination cases may look like putative counterexamples to $\mathrm{PMC}_{4}$. However, intrinsic change can occur between the relational properties of a plurality (i.e. a change in relations between parts). For example, if I'm in a car crash and my spleen gets pushed up against my diaphragm, then my parts underwent an intrinsic change in their relational properties. Consider the propeller table: a plurality of material objects (propeller and pane of glass) underwent an intrinsic change in their relational properties by being combined. The resulting table thereby satisfies $\mathrm{PMC}_{4}$ because its progenitors underwent intrinsic relational modification and the plurality of propeller and glass weren't

10 See Lewis 1999, 111-112 for discussion of the intrinsic/extrinsic distinction. 
a table prior to being combined. Recognizing this, cases of combination aren't counterexamples to $\mathrm{PMC}$, but we can reformulate $\mathrm{PMC}_{4}$ using plural quantification to make this more perspicuous:

$\mathrm{PMC}_{5}$ : If $x$ is an artifact, then there exist some pre-existing material object(s) $y y$ such that $x$ is the result of intentional intrinsic physical modification of $y y$ by some agent(s).

Since there are clear cases of artifact creation by combination, recognizing that as part of a necessary condition on artifactuality is appropriate. ${ }^{11} \mathrm{I}$ therefore take $\mathrm{PMC}_{5}$ to express the principal commitment of the physical modification condition.

\section{Concrete counterexamples to the physical modification condition}

I raise two problems for PMC in this section and the next. First, PMC must reject cases which are intuitively artifacts despite not being intentionally intrinsically physically modified. Second, PMC is incompatible with the possibility of abstract artifacts. I take the first problem to be decisive and the second to raise additional theoretical pressure for the physical modification condition.

$\mathrm{PMC}_{5}$ looks prima facie adequate at capturing the intuitive idea behind the physical modification condition and it seems plausible as a necessary condition on artifactuality. However, below are a number of cases which are intuitively artifacts but don't satisfy $\mathrm{PMC}_{5}$. I consider five cases, but such examples can be easily multiplied.

Driftwood wine rack: a piece of driftwood is taken from a beach and, without being modified, is placed in a kitchen to hold bottles of wine. It holds wine bottles as well as a manufactured wine rack. ${ }^{12}$

Skull paperweight. the skull of a crow from an old museum exhibit is used by the curator as a paperweight on her desk at work. The skull is an effective paperweight and a great conversation starter.

Rock doorstop: an aesthetically pleasing rock from a garden is moved into a house to function as a doorstop. The rock is never modified nor is it ever returned to the garden, and it keeps the door open perfectly well.

Wooden club: a fallen branch is picked up by a farmer and used as a club to fend off wolves from her livestock. The farmer doesn't modify the branch, yet it's an effective weapon.

\footnotetext{
11 A potential counterexample to $\mathrm{PMC}_{5}$ is if one detaches a two-foot high section of a large tree trunk from the rest of the tree by cutting off the stuff above and below it. You declare this large squat log a stool. This looks like there was physical modification that results in an artifact, but not intrinsic physical modification. However, the defender of PMC can argue that the tree trunk itself is the progenitor of the stool and it has undergone intrinsic physical modification. In most cases, there will be some question of what constitutes the artifact's progenitors and answering this question more expansively may avoid potential extensional difficulties.

12 This example is from Lynne Rudder Baker (2007, 53n8).
} 
Belaying device: a 'figure-eight' device was cast from a hunk of metal as an abseiling (descending) device for climbers. However, it was later used as a belaying (ascending) device and the manufacturer then started marketing the figure-eight as both a belaying and abseiling device. The abseiling device underwent no physical modification to become a belaying device. ${ }^{13}$

First, note that plural variables $(x x, y y)$ can be satisfied by a single object as a limiting case of a plurality, so these are genuine counterexamples to $\mathrm{PMC}_{5}$. If these are cases of genuine artifacts, then artifactuality doesn't require physical modification (and thus (P2) in Weitz's argument is false). Ultimately, what we have here is a clash between two competing intuitions: artifacts are the intentional products of intrinsically physically modifying some material objects and some artifacts are made by appropriating pre-existing objects without intrinsically modifying them. Both can't both be true, but which to give up? I think reflection on our artifact practices suggests that artifact creation by appropriation should be retained since it's the more expansive notion. Appropriation is compatible with physical modification. In fact, given the ubiquity of automated and mass production and the increasing technical complexity of modern technological artifacts, appropriation is compatible with the overwhelming majority of artifacts being the result of physical modification. But we should be careful not to infer that because a feature is very common to artifacts that it is essential to artifactuality.

Moreover, the defenders of PMC need some explanation of what's going on in the appropriation cases that doesn't entail their artifactuality. I'll consider the two most plausible explanations in sections 5 and 6. But what reason is there for those who endorse PMC to deny that the appropriation cases are artifacts other than the claim that they aren't modified? There's no salient difference between a manufactured wine rack and the driftwood on the beach appropriated as a wine rack that would prevent the latter from being an artifact. Intentional use of the driftwood as a wine rack seems sufficient, at least in some cases, for artifactuality. ${ }^{14}$ Indeed, walk into any modern furniture store and you're likely to find a piece of driftwood for sale as an overpriced bench or wine rack or sculpture or whatever. ${ }^{15}$

\footnotetext{
13 This example is from Marcel Scheele (2006, 59).

14 See Marcia Eaton 1969 and George Dickie 1984 for discussion of this point.

15 An alternative response is to adopt a Koslicki (2008) or Evnine (2016) inspired view of constitution. On Koslicki's view, the rock is combined with a formal part to become the doorstop, so there is modification, it's just not physical. Evnine's view is similar whereby the intention of the maker counts as the formal cause of the artifact, although while Koslicki accepts appropriation, Evnine does not. Either way, such a view would involve a modification condition, just not a physical one, and thus would be amenable to my view. This approach would be attractive to those who antecedently prefer constitution approaches to material coincidence. However, while they can handle the appropriation cases, the resulting view doesn't involve a physical modification condition, which is the target of this paper and so I won't pursue this line of thought further.
} 
These aren't isolated cases, either. Objects are appropriated as new artifacts in all sorts of contexts. For example, in addition to the figure-eight device, above, Scheele also offers the example of the Pieterskerk in Leiden, The Netherlands: a fifteenth century gothic church that was acquired by a private foundation and turned into a rentable public venue for concerts, conferences and even dinner parties without modification to the existing structure (Scheele 2006, 28-29). ${ }^{16}$ It ceased being a church and became a venue for semi-public events all on the basis of an intentional transfer of ownership. Thus, it isn't only natural objects that can be appropriated as new artifacts. Thomasson (2014, 53-4, n9) offers a hypothetical case: all trade between China and the United States is restricted to the Americans buying large quantities of chopsticks from the Chinese. In China, they are made and used as utensils but in the U.S. they are imported for the sole purpose of being bought and sold as hair ornaments. In such a case, Thomasson takes the Americans to be engaged in a kind of minimal 'making' by exapting the utensils as hair pieces. ${ }^{17}$

One could object that cases like the figure-eight device, the Pieterskerk, and Thomasson's hair ornaments aren't counterexamples to $\mathrm{PMC}_{5}$ because it expresses a condition on being an artifact, not being a new artifact. All those objects already are artifacts so appropriating them as a new artifact kind belaying device, conference venue, and hair ornament, respectively - is irrelevant to $\mathrm{PMC}_{5}$ because they already satisfy the artifactuality condition it expresses in virtue of being the result of physical modification to their progenitors. One can appropriate an artifact as a new artifact without modifying it and the result is trivially an artifact because it already was one. That's compatible with $\mathrm{PMC}_{5}$, so one could reject all such cases as problematic for PMC.

Note two things about this objection. First, the first four appropriation cases are still counterexamples to $\mathrm{PMC}_{5}$ so even if we accept the objection $\mathrm{PMC}_{5}$ still fails. That is, the objects appropriated as artifacts weren't previously artifacts but natural objects, so the act of appropriation which results in their artifactuality shows $\mathrm{PMC}_{5}$ to be false because they weren't modified. Second, $\mathrm{PMC}_{5}$ has the bizarre consequence that two qualitatively indistinguishable objects, both subject to intrinsically identical intentional acts of appropriation, will result in objects of different kinds. Consider a variation on Thomasson's hair ornaments: Americans appropriate Chinese chopsticks as hair ornaments and in virtue of the chopsticks being the result of physical modification when some wood was made into chopsticks, the hair ornaments are artifacts. But imagine we find some sticks that are qualitatively identical (however, unlikely) to a pair of chopsticks and we appropriate them as hair

\footnotetext{
16 See Parsons and Carlson 2008 for further cases like this.

17 But see Lopes 2007 for an alternative approach.
} 
ornaments. According to $\mathrm{PMC}_{5}$, the result of this second, intrinsically identical act of appropriation is not an artifact, but a natural object - a pair of sticks. This seems unprincipled, especially since the first case of physical modification that resulted in the hair ornaments being artifacts was not undertaken by the same agent that made them into hair ornaments but rather by whoever was the maker of the chopsticks. The two cases are similar in all relevant respects except that the chopsticks were the result of intentional physical modification of some pre-existing stuff while the sticks weren't. While $\mathrm{PMC}_{5}$ is thus compatible with cases of artifacts being appropriated as other artifacts, it's not at all clear what explanatory advantage it has given the above consequence.

'Artifact' is also used in various contexts in the special sciences, particularly anthropology, archeology, and evolutionary biology, for various unmodified objects. Some of what anthropologists and archeologists call 'artifacts' are unmodified objects that were clearly used for some purpose or other. These include stone slabs for grinding plants (Mithen 2007, 289-9), rocks used as hammers for opening fruit, grinding food, or working on other rocks to create flaked tools (Schnurrenberger and Bryan 1985), and stones or bones used as decorations or totems. ${ }^{18}$ Like the quotidian cases above, such objects all seem like clear examples of artifacts. ${ }^{19}$ Further, many non-human animals use objects towards specific ends that biologists regard as tool use. ${ }^{20}$ There are documented cases of apes using rocks to open fruit or sticks to spear fish or pry termites out of a log, while elephants have been known to pick up brooms with their trunks and use them as back-scratchers. Cephalopods will use debris on the sea floor, including using the shell of a discarded coconut as mobile armor, as well as broken seashells as portable houses. ${ }^{21}$ These cases, human and non-human alike, show that artifactuality doesn't require intrinsic physical modification. Artifacts can be created by appropriation. ${ }^{22}$

\section{Abstract counterexamples to the physical modification condition}

While I take the above cases to constitute a decisive objection against PMC, there's a further theoretical problem with the view. An increasingly common view, especially in the ontology of art literature, is that there are abstract artifacts. However, PMC entails that no abstract objects can be artifacts because they can't be physically modified since they are, ex hypothesi, not physical objects.

\footnotetext{
18 But see Barham 2013 on the transition to modified objects.

${ }^{19}$ Dickie $(1984,45)$ also appeals to anthropological usage to defend the artifactuality condition on artworks.

${ }^{20}$ Whether any particular animal construction is a result of intentionality or mere stimulus response is an empirical matter for the relevant experts to determine. See Gould 2007 and Thomasson 2007, 67.

21 There are also instances of animals modifying objects. For example, primates stripping branches off a stick or the case of a New Caledonian crow bending a piece of wire to solve a puzzle (Hilpinen, 2011).

22 Evnine (2016) extends his account of artifacts to actions. Artifactual events may occasionally involve appropriation, as when I vote in a faculty meeting by intentionally not raising my hand.
} 
There are two general views in the literature, Platonism and Creationism. Platonism takes repeatable artworks like music, literature and film to be abstract objects which exist necessarily and are creatively discovered (e.g. Dodd 2007). The appeal to Platonism is to explain the repeatability of such entities. Since musical works, literature, and film seem to be clear cases of artifacts, if we reject PMC then the Platonist can easily accommodate their artifactuality. That is, abstract objects can be treated in the same manner as the appropriation cases: an agent appropriates a pre-existing object like a piece of driftwood or an abstract type of sound sequence as a new artifact, such as a wine rack or piece of music, respectively. ${ }^{23}$

For the Creationist, by contrast, such works exist contingently and are created and come into existence by the concrete acts of their makers (e.g. Thomasson 1999, Friedell 2016). A composer writes a score, an author writes a manuscript, and an abstract artifact, the musical work or novel, comes into existence. Creationism has become widespread in the literature and is being used to explain all sorts of entities, including words (Irmak 2018), software (Irmak 2012), and even internet memes (Evnine 2018). However, if PMC is true, then on neither view are the works themselves artifacts, since abstract objects are not physical objects. The Brothers Karamazov isn't an artifact, but copies of it are. This seems counterintuitive since novels and musical works seem like paradigm cases of artifacts in virtue of being the products of intentional action. ${ }^{24}$

While I don't take the problem of abstract artifacts to be decisive against PMC since not everyone buys into abstracta, given that Creationism in particular is quickly becoming the de facto position in the literature and is being extended to all sorts of entities, from fictional characters and stories to games, words, software, flags, and institutional kinds, a theory of artifacts that isn't in tension with it is in a prima facie better explanatory position. ${ }^{25}$

\section{Objection: being a $\mathrm{k}$ vs. being used as a $\mathrm{k}$}

The defender of PMC needs a way to resist the appropriation cases in section 3. There are two plausible ways to do this, which I consider in turn. First, they might be rejected as genuine cases of something becoming an artifact but are rather cases of pre-existing objects being used as some artifactual kind. Ordinary language marks a distinction between the following, where ' $K$ ' is any artifact kind:

(a) Being a $K$

\footnotetext{
${ }^{23}$ Levinson's (1980) account of music as indicated types can be understood in this way.

${ }^{24}$ Although Davies (1991, 139-141) argues otherwise. Mag Uidhir (2013, ch. 4) also argues that the intention-dependence of artifacts and artworks rules out the possibility of abstract artifacts, but see Irmak 2020, 2021 for responses.

25 One major concern with abstract artifacts in either form is that they appear to require that abstracta enter into causal relations. For concerns with this requirement see Juvshik 2018, 2020 and Friedell 2019.
} 
(b) Being used as a $K$

We intuitively think that using a teapot as a paperweight doesn't make it a paperweight. Similarly, taking a rock out of the garden and propping open a door with it isn't a case of making a doorstop, but is simply a case of using a rock as a doorstop. Such cases are rampant in our interactions with the built world. We use screwdrivers to open paint cans, coffee mugs to secure papers, palm trees as parasols, and even paperclips as earrings. Thus, these cases, as well as those discussed in section 3 , might be rejected as genuine artifacts on this basis.

This sort of argument has been deployed by Dipert (1993, 26-27), and more recently by Evnine (2016, 86, 132-133) and Hick (2019, 63n6). ${ }^{26}$ In responding to Weitz, Marcia Eaton (1969) appears to accept the view that any amount of use, however one-off, is sufficient to make an object into a $K$. While I grant that there is such a distinction, unlike Eaton I share the intuition that a one-off use of a teapot as a paperweight doesn't make it a paperweight. However, I think there are cases where using something as a $K$ for long enough or with broad communal recognition is sufficient to make it a $K$. Where exactly to draw the line is certainly vague, but there are cases where this happens. A one-off use of a teapot as a paperweight doesn't make it a paperweight, but intuitions are different in a case of a rock that is brought in to be used as a doorstop, it's never brought outside again, and it's used as a doorstop by all members of the household. This seems to make it a doorstop.

One could argue that this only succeeds in cases where the appropriated object is fully natural - the teapot is already an artifact. However, Scheele's (2006, 29-31) examples of the Pieterskerk and the figure-eight abseiling device appropriated and used as a belaying device shows that with sufficient communal uptake an artifact can, without being modified, become a member of a new artifact kind.

Therefore, there are cases where continued and entrenched use of an unmodified object, be it natural or artifactual, results in the object becoming an artifact. What seems to matter is whether new norms of use, including norms of who the proper audience/users are, what the proper context of use is, and what the function of the object is, develop around the practice of using the object as a $K$ (if it's a new kind of artifact) or whether the norms of use governing $K s$ (if $K s$ already exist) become applied to the new object. Context of use is particularly important: left on the beach, the driftwood won't become an artwork, no matter how much one intends it to become one. Similarly, appropriating a rock as a doorstop can genuinely make it into a doorstop if the use is consistent and in line with our

${ }^{26}$ Dipert $(1993,26)$ gives the example of using a stone to step across a river, Evnine $(2016,132)$ gives the example of using a table as a desk, and Hick $(2019,63)$ gives the example of using a hammer as a paperweight. 
general norms governing doorstops and it's placed in a building, near a door (see Thomasson 2014 for development and discussion of this view). Indeed, notice that if you take my rock doorstop back out to the garden, you're subject to rebuke: you're misusing the object by not treating it as doorstops are normally treated and I can justifiably tell you not to do that. Such rebukes carry normative force because the rock has genuinely become a doorstop. ${ }^{27}$ Moreover, some sort of communal acceptance by the relevant social group appears to override denials of artifact status. If everyone in my house uses, treats, and regards the rock as a doorstop this overrules anyone who comes into the house and denies its doorstop status. The relevant social group may be very broad, as when the climbing community accepts and treats the figure-eight device as a belaying device which makes the figure-eight device a belaying device. Therefore, there are clear cases where unmodified objects genuinely become a $\mathrm{K}^{28}$

There's a related worry that the being a K/being used as a $K$ distinction overgeneralizes and thereby undermines Weitz's driftwood intuition. We could equally argue that the driftwood doesn't become an artwork when it's placed in the gallery but is merely used as an artwork when placed in a gallery. ${ }^{29}$ There appears to be nothing distinguishing between such a case and the case of the teapot used as a paperweight except that communal acceptance renders the driftwood an artwork, in which case there's nothing stopping us from saying the same thing about non-art artifact cases. That is, if broad communal acceptance and entrenched use can make an unmodified object into an artwork, then it seems the same can occur with a non-art artifact. The first appropriation case involves a piece of driftwood becoming a wine rack. If driftwood can become an artwork through sufficient intentional use, then there's no principled reason for denying that driftwood can become a wine rack or a coffee table or whatever in the same manner. ${ }^{30}$ As a result, while there is a genuine distinction between being a $K$ and being used as a $K$, it doesn't track physical modification.

\section{Objection: swamp cases}

\footnotetext{
${ }^{27}$ Hick (2019, 63 and n6) disputes this. He argues that it's perfectly appropriate to use a hammer as a paperweight even though it isn't the intended use of the hammer. But this seems too quick since it ignores questions of ownership and it seems to depend on the function in question: using a hammer as a paperweight seems harmless but using a hammer to stir soup or as a gearshift seems objectionable and it depends on whose hammer it is. Nonetheless, one may not share the intuition that putting the rock outside is misusing it, in which case we can treat such rebukes as defeasible evidence for it being a doorstop.

${ }^{28}$ Peter McLaughlin (2001, 54, passim) calls these cases of 'virtual assembly'.

${ }^{29}$ See Hick 2019 for an excellent discussion of using things as art.

${ }^{30}$ Evnine (2016, 132-133) rejects appropriation for artifacts generally but allows it for the case of ready-made artworks (2013). Perhaps one could maintain that there's a principled difference between artworks and artifacts whereby the former are sui generis kinds of the latter, as Levinson (2007) argues. See also Hick 2019, 70 and passim for discussion.
} 
The second way to resist the counterexamples in section 3 is to deny that the inference from ' $x$ is a doorstop' to ' $x$ is an artifact' is valid. Something could be a chair or doorstop or camera or whatever but not an artifact. This maintains that the appropriation cases fall under their respective kinds (wine rack, paperweight, doorstop, club, and belaying device) but denies that they're artifacts.

In the context of defending intention-dependence as a condition on artworks and artifacts, Christy Mag Uidhir (2013, 99-100) takes this approach when considering swamp cases. Imagine lightning strikes a log in a swamp and the atoms of the log get rearranged so they're an intrinsic duplicate of a camera. Mag Uidhir argues that this is, in fact, a camera, but isn't an artifact. Mag Uidhir's reasoning is that the swamp camera can function just like regular cameras. As a result, camera is a purely functional kind (108). According to Mag Uidhir, since the swamp camera isn't intention-dependent, it's not an artifact, but since it can function as cameras typically function, it is, intuitively, a camera. This doesn't seem particular to cameras, so one could extend it to all putative artifact subkinds like chair, doorstop, and wine rack. Mag Uidhir's view seems to have a lot going for it. It would preserve both the intuition that the rock is a doorstop and the intuition that artifacts are essentially things modified by humans. The idea is that putative subkinds of artifacts are purely functional kinds, so I can make a doorstop or chair by appropriation but I can't make an artifact without physically modifying it.

Despite the attractiveness of this position it faces an overwhelming problem. If such kinds are functional kinds, then what account of function could accommodate Mag Uidhir's claim that the swamp camera is a camera? Let's say that the function of (non-digital) cameras is roughly to imprint an image onto a photosensitive surface. There are two main accounts of function, Ruth Millikan's (1984) proper functions and the actual causal powers view. ${ }^{31}$ An object's proper function is what that thing is for, which is determined by its history of selection and reproduction (e.g. my car is for transportation because previous cars were successful as modes of transportation and were reproduced because of that success). ${ }^{32}$ Proper functions are clearly inadequate because this particular camera wasn't created by a process of selection because previous cameras successfully performed their function. That is, the swamp camera came into existence by a freak lightning strike, so there's no history of production and reproduction, nor any selection or copying mechanism, so ipso facto it can't have the function of normal cameras.

\footnotetext{
31 See Thomasson 2007, 57-58 for discussion of the actual causal powers view.

32 Novel prototypes have 'derived' proper functions that derive from the intentions of their makers. See Millikan 1984, 1314.
} 
That leaves the actual causal powers view, according to which my car has the function of transportation because it has the actual causal capacities to transport goods and people from one place to another. The swamp camera is a camera because of the causal powers that enable it to function as cameras normally function. This seems to be what Mag Uidhir has in mind in claiming that the swamp camera can function in this way. ${ }^{33}$

This view has two main problems, one with the view itself and the other with Mag Uidhir's position, specifically. First, malfunction is widely regarded as a desideratum for any theory of function: a camera can fail to work properly. ${ }^{34}$ Intuitively, a broken camera still has the function of taking pictures. The actual causal powers view entails not that it's malfunctioning but that it doesn't have that function at all in virtue of lacking the requisite causal powers. Mag Uidhir would have to say that an otherwise intrinsic duplicate swamp camera that can't take pictures isn't a camera and that when actual cameras break they simply cease having the function of taking pictures and perhaps cease to be cameras at all. The latter is especially unintuitive and clearly in tension with our actual practices.

Second, Mag Uidhir's view entails that any object that has the causal powers to perform some function $F$ falls under the functional kind associated with $F$. Cars are typically regarded as modes of transportation but they can also make orange juice by running over oranges. The actual causal powers view would say that cars are juicers in virtue of their causal powers. Not only are swamp cameras genuine cameras and cars juicers, but swamp toothpicks are toothpicks. It's not restricted to swamp cases. Shards of glass are shivs, logs are benches, a piece of driftwood is a wine rack, rocks on Mars are doorstops, not potentially but actually. Mag Uidhir's view has the consequence that any given object actually falls under a myriad of functional kinds simply in virtue of its causal powers, even if it's never used to perform that function nor if any agents ever interact with it. ${ }^{35}$ The rock on Mars that no one ever sits on is not a chair. Maybe if a weary astronaut takes a seat on it in the future she makes it into a chair or at the least uses it as a chair, but it isn't a chair now merely because it can seat a single person.

With respect to the cases from section 3, if one reasons that they are doorstops, wine racks or whatever but not artifacts on the basis that they can (1) function as such kinds function but (2) weren't physically modified, then it seems we have to say that all sorts of things are chairs and doorstops and wine racks because they can function as such things normally function. This vastly overgenerates the

\footnotetext{
33 The actual causal powers view also appears in Cummins's (1975) account of system functions, whereby we understand something's function in terms of its actual causal role in a system. Since system functions inherit the problems of the actual causal powers view, I don't consider them separately.

34 See Preston 2009 for a discussion of artifact malfunction.

35 See also Khalidi 2016, 232 for discussion of similar cases.
} 
number of chairs, doorstops, and wine racks in the universe. There's no account of function that will make room for swamp cameras being cameras without considerable theoretical baggage. ${ }^{36}$

Nevertheless, there is an intermediate position available that may save the virtues of Mag Uidhir's account while avoiding these difficulties. One could maintain that the swamp camera isn't an artifact or a camera when it first comes into existence but that it can be appropriated as a camera but not thereby become an artifact. Such a view maintains that appropriation is possible but only in producing functional kinds, not artifacts. This view avoids the proliferation of functional objects because it ties them to intention-dependence. The swamp camera is just a natural object when it comes into existence but in virtue of being appropriated it becomes a functional object, namely a camera. It would only become an artifact if an agent physically modified it. As a result, both artifacts and functional kinds are necessarily intention-dependent, but artifacts must additionally meet the physical modification condition and so the appropriation cases in section 3 wouldn't be counterexamples to PMC.

There is a major problem with this approach. On this view a doorstop and wine rack which resulted from physical modification are artifacts. But doorstops and wine racks which didn't result from physical modification are not artifacts. Such a move saves PMC as a condition on artifacts but it does so by sheer definitional fiat. It's hard to see, however, what the theoretical motivation for such a stipulation would be (I'll further discuss such definitional moves in section 8). Moreover, this approach loses all contact with our classificatory behaviour. Before we regarded any particular doorstop or wine rack or camera or whatever as an artifact we'd first have to determine whether it was the result of physical modification. If I discover that a bit of smoothness on the driftwood wine rack that I took to be sanded down so the bottles are more stable was in fact produced naturally by the motion of the tides as it lay on the beach, then I'd have to withdraw my claim that it was an artifact. But we don't seem to do this. However, we do withdraw our claim of artifactuality if we discover that the thing found on the beach or in the swamp, regardless of how much putative intentional design it exhibits, had no human involvement whatsoever - not in its creation and not in being appropriated either.

As a result, we should accept the validity of the inference from ' $x$ is a chair' to ' $x$ is an artifact' and further accept that artifacts don't need to be the result of physical modification but can be made through acts of appropriation. Indeed, recognizing appropriational making of artifacts can easily account for these intuitions. Mag Uidhir and others who deny the inference from subkind to artifact

\footnotetext{
36 Goodman (2020, 7-8) recognizes this consequence, albeit in a different context, and opts to simply bite the bullet and recognize way more things as chairs and tables and juicers and cameras and whatever than we normally do.
} 
find themselves in an impoverished explanatory position which is simultaneously extensionally inadequate. I doubt Mag Uidhir has the intuition that a swamp toothpick is a toothpick simply because it can function as toothpicks function. By choosing cameras as an example, intuitions may be swayed by apparent technical complexity. There may be an implicit attribution of intentional design that's tracking the perceived complexity of the swamp camera that's absent in the case of a swamp toothpick. ${ }^{37}$ By accepting artifact creation by appropriation, we can maintain that the swamp camera isn't a camera when it's first created but it can be appropriated as one by some agent.

\section{Objection: appropriation is too easy}

Despite the intuitive appeal of appropriation, there's a deeper worry that some may have about it, namely that it entails or allows the possibility for, our merely thinking or speaking things into existence. Such concerns often come from realist quarters which take issue with an ontology that includes minddependent entities, in general. For various reasons, it's thought that to be real or really real requires an entity to be mind-independent. Any view that allows something to come about merely by our thinking or speaking about it as such is ontologically impoverished - such entities aren't really part of the furniture of the world. ${ }^{38}$ For example, Dean Zimmerman, responding to Baker's view, remarks that:

Baker thinks we sometimes bring things into existence by thinking about them - at least, this follows from her view if objects can become artifacts (tools and works of art and monuments, for instance) simply by our thinking about them as such. A piece of conveniently shaped driftwood becomes a coffee table by being brushed off and brought into a house, a urinal becomes a sculpture when hung on a wall in a museum and given a title ... But do we really believe that anything new comes into existence when we do such things? (2002, 333-334)

This passage doesn't really contain an argument. Nonetheless, Zimmerman seems to be suggesting that the driftwood appropriated as a coffee table isn't really a coffee table - merely conceptualizing it as a coffee table doesn't make it one. This would make appropriation too easy or too cheap: we could go around thinking anything into an artifact. For example, if I just look at a branch on the ground and think that it'd make a good walking stick, it seems absurd to say that I've made it into a walking stick. Zimmerman's worry, and other realist worries like it, aren't just aimed at artifacts, but are general worries about mind-dependent or intention-dependent phenomena. ${ }^{39}$

\footnotetext{
37 See Juvshik 2021 a for a discussion of such intuitions.

38 See, for example, Wiggins 2001, Zimmerman 2002, Elder 2007, 2014, and Lowe 2014 for this sort of objection.

39 See Baker 2007, Thomasson 2007, 2014, and Evnine 2016 for responses to these sorts of realist worries about artifacts.
} 
Thankfully, we needn't endorse Zimmerman's caricatured view of appropriation. While I can't address general realist worries about mind- or intention-dependence here, I can sketch some features of appropriation and three broad conditions for successful appropriation that they suggest. In response to the being a $K /$ being used as a $K$ distinction, I suggested that not any passing use will turn the latter into the former. To avoid Zimmerman's charge, we need to further specify what successful appropriation involves.

First, since it seems that I can't just look at a branch and think it into a walking stick, some act or attempt seems necessary. A mere intention isn't sufficient; ${ }^{40} \mathrm{I}$ at least need to pick the branch up and use it as a walking stick or brush it off or bring it home and tell others that it's my new walking stick. ${ }^{41}$ Since there seems to be a genuine distinction between using something as a $K$ and being a $K$, this presumably involves different intentions. To use something as a $K$, I intend that the use be temporary and in some sense the content of my intention isn't 'transformative' - I don't intend to appropriate. By contrast, becoming a $K$ through appropriation requires an intention to do so; the appropriational act isn't intended to be temporary and this can be reinforced through repeated use. For example, I may use my teapot as a temporary paperweight, not intending that it remain on my desk for this purpose in perpetuity. However, I can appropriate a chunk of granite as a paperweight with the intention that this be permanent; the granite remains on my desk, and I routinely use it as a paperweight and tell others that this is what it is. Of course, the line between being a $K$ and being used as a $K$ is certainly vague. Repeated use seems important in many cases, but there doesn't seem to be a definitive amount of use that is sufficient for becoming a $K$. If I use the teapot as a paperweight only once it doesn't become a paperweight. If I intend that my teapot become a paperweight and only use it as a paperweight for my entire life, it seems to genuinely become one. But things are less clear if I use it twenty consecutive times as a paperweight. Perhaps the content of my intention may itself be vague in such cases. The requisite amount of use will likely vary by context and the particular artifact kind in question.

An individual's intention to appropriate will generally be easier for natural objects, such as the chunk of granite. The teapot resists appropriation, even through repeated use, because it's already an artifact. As a kind of artifact, it was intended to function in a certain way relevant to its kind. The

\footnotetext{
${ }^{40}$ Mag Uidhir (2013) similarly argues that a mere intention isn't enough to make an artwork but that there must be an attempt. Since attempts are intentional, an attempt to $\phi$ entails an intention to $\phi$ but not vice versa since I can intend to $\phi$ without doing anything else, in which case I would fail to execute my intention. See also Xhignesse 2020 for discussion.

${ }^{41}$ Borgo and Vieu (2009) seem to think that merely thinking of a branch as a walking stick is sufficient to make it a walking stick.
} 
intended function of an artifact takes precedence over the imposition of a new artifact kind on the object. One thing that can overrule a maker's intention is social pressure or communal acceptance, as in Thomasson's (2014, 53-54) example of Chinese chopsticks being used exclusively in the United States as hair ornaments. ${ }^{42}$

This leads to the second feature of successful appropriation. Acceptance of successful appropriation by the relevant community or social group often seems to play a central role in determining whether any appropriational act is successful. Consider Weitz's driftwood sculpture: moving it to an art gallery and having it accepted as art (and a sculpture, specifically) by the relevant group of art users and appreciators - the artworld public - seems sufficient for appropriating the driftwood as a sculpture. Similarly, in the case of my rock doorstop, if my entire family accepts it and treats it as a doorstop, then my intention to appropriate the rock as a doorstop appears to be successful. The rock doorstop thereby becomes subject to norms of use, treatment, and regard common to doorstops: it is to be used and treated in a certain way and it's to be regarded as a doorstop. Arranging it alongside other rocks in a rock garden is, in some sense, to misuse it, while moving it outside is mistreating it. ${ }^{43}$

Communal acceptance thereby plays a crucial role in many cases of appropriation. Of course, I can also appropriate the rock as a doorstop 'privately' if I live alone and no one else interacts with it, so long as I have the relevant intention. What's unclear is whether communal acceptance is alone sufficient or if the intention to appropriate is necessary. For example, if I only intend to use the driftwood as a sculpture but the artworld public accepts it as a sculpture (not just temporarily, but as an act of genuine artistic appropriation), it's not clear whether it has become a sculpture. I'm inclined to think it has become a sculpture, despite my intention towards mere use. Something similar could happen with the rock doorstop: if I only intend to use it temporarily as a doorstop but my family accepts it and treats it as a doorstop, then it seems to genuinely become a doorstop. There are two ways one could go here. First, makers may be wrong about their intentions. Perhaps I only intend to use the rock as a doorstop but the relevant social group accepts my intentional action as successful doorstop appropriation. In this case, I was mistaken about what my intention brought about or what my intention actually was. Second, we could view the communal acceptance as a sort of distinct intention to appropriate. Thus, while I only intended to use the rock as a doorstop, my family members's intention to appropriate it as a doorstop by intending to treat it and use it as one is the real

\footnotetext{
42 I think it's indeterminate whether they're just hair ornaments or both utensils and hair ornaments.

${ }^{43}$ See Franssen 2006 for discussion of various normative dimensions of artifacts.
} 
act of appropriation. My intention of mere use was thereby overruled by my social group. I'm not sure which explanation is better for these sorts of cases but the matter need not get settled here.

A corollary of the preceding remarks involves the scope of appropriation that individuals and communities are capable of. Consider Scheele's $(2006,59)$ example of the figure-eight device that was manufactured as an abseiling device but which was appropriated by the climbing community as a belaying device. Here we have a case where the entire artifact kind, figure-eight device, is eventually appropriated as a distinct artifact kind. This sort of kind-level appropriation seems to require the acceptance of the relevant community. A lone individual can appropriate an individual artifact as a distinct kind of artifact, but not, presumably, appropriate the entire kind. Appropriation of the kind requires that new norms of use, treatment, and regard are accepted and instituted by the relevant social group, although this will be initiated by an individual's act of appropriation.

Despite the foregoing, it may be argued that communities or social groups can fail to appropriate pre-existing artifacts as new artifacts despite communal acceptance. For example, consider an isolated culture living on a desert island where a teapot washes ashore. Mistaking the teapot for a flowerpot, the desert island culture uses it as a flowerpot. Outsiders visit one day and inform the group that the object belongs to a set of fine China and is for serving tea, not for growing and displaying flowers. In such a case, we would say that the desert island society discovered that the artifact is a teapot, not that they appropriated a teapot as a flowerpot. Nor is this a merely hypothetical case, as archeologists routinely misclassify artifacts, such as mistakenly thinking something is a crown when it's in fact part of the handle of a bucket. ${ }^{44}$

While it may seem that this poses a difficulty for my account of appropriation via communal acceptance, I don't think it actually does, for two reasons. First, the conditions on appropriation can be vague or indeterminate, as with the vague boundary between using as and appropriating. This isn't a vice of the account but rather just reflects our actual artifact practices. So if it's vague or indeterminate whether the desert island community has appropriated the teapot as a flowerpot, then this just reflects the vagueness or indeterminacy in that community's flowerpot practices. Moreover, since appropriation can occur via communal acceptance, there's nothing to suggest that it can't be reversed in a similar way - the desert island community could, upon learning that it's originally a teapot, revert

\footnotetext{
${ }^{44}$ A fictional version of this appears in David Macaulay's Motel of the Mysteries (1979) where thousands of years in the future archeologists discover a bunch of junk from a motel and mistakenly think it's treasure on a par with that found in the tomb of Tutankhamun.
} 
it to teapot status via communal acceptance (or rather, a recognition that they were mistaken), though of course in such cases we may well want to say that it's both a teapot and a flowerpot. ${ }^{45}$

However, there's a second, more important thing to note about this case: the desert island community didn't intend to appropriate the teapot as a flowerpot. Rather, they mistakenly thought it was a flowerpot all along. Thus, there's an important difference between appropriating an artifact as another artifact and mistakenly using one artifact as if it were something else. The content of one's intention matters. Compare a case where one appropriates an old metal lampshade as a bird bath: maybe it's both a lampshade and a bird bath, but more importantly you know that it was/is a lampshade and intend to turn it into a bird bath by flipping it over and putting it on a plinth outside. Things would be very different if you found the lampshade on the side of the road and thought it was a birdbath all along - in this case you would be mistaken that it's a birdbath. ${ }^{46}$ Thus, one can intend to use something as a $K$ because one thinks it is a $K$, one can intend to use something as a $K$ temporarily, knowing it's not a $K$, and one can intend to appropriate something as a $K$, knowing it's not (currently) a $K$. Appropriation involves knowing that the artifact is of a particular kind and intending that it be a member of a different artifact kind. ${ }^{47}$ This is compatible with being mistaken about what artifact kind any given artifact belongs to. As a result, we can say that the desert island community is simply wrong that the teapot is a flowerpot. We can say the same thing in the archeology case: archeologists intend to classify artifacts by the intentions of their makers and this task is difficult precisely because their makers aren't around and the artifacts are removed from their social context. Archeologists can therefore get such classifications wrong, as they frequently do. But archeologists are not intending to appropriate old artifacts from extinct cultures as a distinct kind of artifact - in fact, this would be inimical to the goal of archeology. Therefore, communal acceptance can indeed be involved in appropriating one artifact as a member of a different artifact kind, but such communal acceptance requires communal knowledge that the object is a member of a distinct artifact kind (even if they don't know what kind) and they

\footnotetext{
${ }^{45}$ Compare this with a case where they find the teapot and take it to be an idol of their god, imbuing it with central religious significance. They would be far less likely to say that they discovered it was a teapot but would rather insist that it's a (perhaps appropriated) idol. In some such cases, communal acceptance of appropriation can overrule the original maker's intention.

46 This also shows the close connection between appropriation and recycling or reuse. I'm inclined to think recycling involves some small modification to a pre-existing artifact in order to make it into a new artifact, whereas appropriation does so without modification. Reuse could either refer to appropriation or to using as. See Preston 2009 for discussion of reuse and recycling.

${ }^{47}$ Compare Thomasson's case of Americans appropriating chopsticks as hair pieces or Scheele's case of the figure-eight device being appropriated as a belaying device and the church being appropriated as an event-hall. We wouldn't say that these social groups are wrong that the artifact is an event hall because they knew it was a church from the get-go and are intentionally appropriating it as a different artifact kind.
} 
intend to appropriate it as a different artifact kind. Epistemic considerations are key in successful appropriation.

The third feature on successful appropriation is that, regardless of whether an act of appropriation only involves an individual or also involves their social group or other relevant community, successful appropriation seems to require that the object appropriated is actually physically capable of performing the function it is being appropriated to perform. A teapot or a hunk of granite can be appropriated as a paperweight because they're capable of performing the function of paperweights - they have sufficient mass to hold down papers. ${ }^{48}$ But trying to appropriate a toothpick or a feather as a paperweight seems doomed to fail: no matter how strong my intention to make a paperweight out of these objects, they're simply too light to be paperweights. It's unclear whether communal acceptance can prevail here: maybe if the entire culture routinely treated feathers as paperweights even though they can't perform that function, then this would make them paperweights. ${ }^{49}$ I'm not sure what to say about such a case, but again, it doesn't need to be settled here.

What's important to note is that the actual causal powers of an object place strong constraints on what can be appropriated as what. Since many artifacts are enormously complex, such as cellphones or airplanes or microwaves, it's simply unlikely that any object would occur naturally that could be appropriated as these kinds of artifacts. Philosophers are fond of swamp cases, so of course a swampcellphone could be appropriated as a cellphone, but my point is merely how unlikely a swampcellphone is in the first place. The scope of successful appropriation is far wider when we consider appropriating pre-existing artifacts as members of new artifact kinds. In fact, the function of many artifacts shifts over time in a way similar to appropriation. Sports Utility Vehicles (SUVs) were intended to be used for transporting sports equipment during outdoor excursions, but now are predominantly used by suburban families for everyday driving because of their expansive seating and cargo capacity. ${ }^{50}$ Whether this particular example is a case of appropriation or of a shift in function doesn't matter - they're two sides of the same coin - the point is that manufactured artifacts are often

\footnotetext{
48 I don't mean to suggest that paperweights are essentially for holding down papers, as paradoxical as that may sound. See Juvshik 2021b for discussion of this issue.

49 This could be a case of what Preston (2009, 217-218) calls phantom functions - functions that the artifact kind is reproduced to serve even though it's physically impossible for it to perform that function (e.g. the beaked plague masks of the seventeenth century).

50 This example is from Elder 2014, 35.
} 
more technically complex so have a broader range of appropriational possibilities. A rock can't be appropriated as a space shuttle engine but a V6 rocket can. ${ }^{51}$

This last point also suggests why the physical modification condition (PMC) is so appealing. I suggested at the outset that a trio of features form an attractive account of artifact essences: intentiondependence, function, and physical modification. What we're now in a position to see is that the latter is just a quick way of getting at the former. Our goals are often complex and there are many means to achieving them. If I want to attach a nail to the wall so I can hang a picture, one way is to hammer it in with a rock from the garden. However, this hammering will be easier if I flatten the rock and attach it to a wooden handle so I have better leverage. Both appropriating a rock as a hammer and constructing a hammer out of various objects will allow me to achieve my goal (as will buying a hammer made by someone else), but one will do so more efficiently (as well as providing me with a hammer for future use). If an artifact is physically modified, it's a clear indication that it depends on its maker's intentions and that it was made with some goal or purpose in mind. Intention-dependence and function are less obvious in the case of an appropriated artifact, often because they lack physical markers of their maker's intentions which we rely on as evidence of the kind of thing that they are. We see the modification that took place and infer that it resulted intentionally and for some purpose. ${ }^{52}$ We don't see this with a mere rock or piece of driftwood until it's placed in the right context (beside a door or in a gallery) or we are given testimonial evidence of appropriation by, say, the maker telling us that she intended to appropriate the rock or driftwood in a certain way. This epistemic feature of artifacts deceives us into thinking that physical modification is a metaphysical (read: essential) feature of artifactuality.

There are thus fairly strong constraints on successful appropriation. We can't just think about an object in passing for it to become an artifact. I pointed to three general conditions on appropriation:

1. An act or attempt

2. Social acceptance

3. Physical capability

The first and third conditions are presumably necessary while the second is arguably sufficient. As a result, we have fairly strong conditions on successful appropriation - not just any old thought or

\footnotetext{
${ }^{51}$ In another sense, a rock can be used for far more than a V6 rocket, such as a paperweight, hammer, weapon, decoration, etc. The technical complexity of a V6 that allows it to be a rocket engine simultaneously limits its (appropriate) uses.

52 Of course, we can also be mistaken about apparent intelligent design. If we came across the swamp-cellphone we'd assume it was built by someone. It would take very strong evidence for us to accept that coalescing swamp gases are responsible for such an object.
} 
intention will result in successful appropriation. The two examples Zimmerman gives happen to be of successful appropriation: brushing off the driftwood and bringing it home involves the appropriate intention and attempt, the driftwood possesses the necessary physical capabilities to function as a coffee table and presumably others who encounter it will treat it as a coffee table. The same holds for the urinal appropriated as a sculpture. While Zimmerman's examples appear to involve successful, and therefore unobjectionable, appropriation, his general worry that mere thought is sufficient for appropriation is off the mark. There are relatively strong constraints on successful appropriation.

\section{Conclusion}

I've offered a perspicuous formulation of the physical modification condition and argued that there are clear cases of artifacts which don't satisfy this condition, both concrete and abstract. At base, we have a clash of intuitions regarding an essential characteristic of artifacts: whether they must be the result of intentional, intrinsic physical modification. Since intuitions seem to support the possibility of creating an artifact by appropriating a pre-existing object without modifying it and considering that appropriation is the more expansive notion, allowing the possibility of both modified and unmodified artifacts, we have good reason to accept appropriation. However, in order to reject appropriation, the defender of the physical modification condition needs an alternative way of explaining the counterexamples I've raised, such as the driftwood wine rack or rock doorstop. I considered the two most plausible approaches: appealing to the distinction between being $a K$ and being used as $a K$ and arguing that my alleged counterexamples are cases of purely functional kinds but are not artifacts. Both face serious difficulties, so in the absence of a plausible alternative explanation, I suggest we accept appropriational artifacts and concomitantly reject the physical modification condition on artifactuality. Moreover, I sketched some conditions on successful appropriation in response to the objection that appropriation is too easy - it allows us to think or speak objects into existence - which shows that there are relatively strong constraints on appropriating objects as artifacts.

Nevertheless, one may argue that this is a mere verbal dispute. For example, someone may object that "appropriated artifacts" aren't artifacts because they aren't really created and being created is partly definitive of artifactuality. Such a person may then say that the dispute is really about how we should use the word 'artifact', noting that it's fine to call appropriated objects artifacts but that the physical modification condition still holds for a more restricted sense of 'artifact' (similar to the proposal considered at the end of section 6). We do in fact see such prescriptive proposals in anthropology. For example, Oswalt $(1976,18 \mathrm{ff}$.) distinguishes between 'naturefacts' and 'artifacts' 
where the former are appropriated natural objects and the latter are modified objects, and so 'artifact' is reserved for those objects that satisfy the physical modification condition. However, this is a domain-specific proposal for a prescriptive use of 'artifact' which is motivated by epistemic considerations - anthropologists face the general difficulty of distinguishing between appropriated objects and natural objects - so using a distinct term for them may be explanatorily or theoretically useful. However, this isn't the only prescriptive proposal for 'artifact'. Dipert (1993, 23-33) makes a tripartite distinction between 'instrument', 'tool', and 'artifact': instruments are objects that are intentionally used for some purpose, tools are intentionally modified instruments, and artifacts are objects intended to be recognized as tools. Thus, for Dipert, 'artifact' has an ineliminable social aspect - artifacts are intentionally modified objects where part of the intention in modifying them is that others recognize that the object was modified for some particular purpose. This social aspect of artifacts is quite controversial, but the point is merely that any claim to verbal dispute runs the risk of going beyond what the physical modification theorist wants. But Dipert, like Oswalt, is making these distinctions for primarily explanatory reasons. As a result, we can maintain that in both the case of Oswalt's naturefacts and artifacts and Dipert's instruments, tools, and artifacts, there is no ontological or metaphysical difference between these categories. Rather, they are just making finer-grained conceptual distinctions for the sake of inquiry and so in a sense all of the things they're talking about are artifacts. Indeed, part of what I've been arguing is that there is no metaphysical difference between a physically modified driftwood wine rack and an appropriated driftwood wine rack, so such prescriptive verbal maneuvers aren't tracking something metaphysically relevant. By contrast, I take my approach to be descriptive and thereby roughly track the folk usage of 'artifact' and cognate concepts like 'tool', 'instrument', and 'technology'. ${ }^{53} \mathrm{I}$ 'm aiming to describe the concept of artifact that's operative in our general artifact practices, which is an expansive concept that includes appropriation. Therefore, any prescriptive proposal for 'artifact' can be thought of as a restriction of the general concept that I'm explicating, typically motivated by explanatory concerns but not altogether germane to my descriptive project.

While much more can and should be said about appropriated artifacts, I've attempted to lay out some conditions on successful appropriation, which in turn can help us understand why the physical modification condition looks plausible in the first place. Appropriating objects as artifacts

\footnotetext{
53 There is a distinct sense of 'artifact' in locutions like 'pollution is an artifact of industrial activity'. This sort of use seems to just involve something being a causal consequence of something else, whether intentional or not. See Dipert 1993, 3337 and Evnine 2016, 128 for discussion.
} 
isn't alien or objectionable but is rather quite mundane. This doesn't make appropriation too easy nor our conceptual capacities too powerful. It just recognizes a pre-existing and commonplace feature of our artifact practices: we appropriate pre-existing objects as new artifacts. Artifactualization doesn't require physical modification.

Acknowledgements: Thanks to Selim Berker, Tim Button, Stephen Davies, David Friedell, Patrick Grafton-Cardwell, Hilary Kornblith, Dominic Lopes, Christy Mag Uidhir, Ned Markosian, Amie Thomasson, and audiences in Albany, Montreal, and Phoenix for comments and criticisms on previous versions of this paper.

\section{References}

Amrei Bahr. 2019. "What the Mona Lisa and a Screwdriver Have in Common." Grazer Philosophische Studien 96: 81-104.

Lynn Rudder Baker. 2007. The Metaphysics of Everyday Life: An Essay in Practical Realism. Cambridge: Cambridge University Press.

Lawrence Barham. 2013. From Hand to Handle: The First Industrial Revolution. Oxford: OUP.

Paul Bloom. 1996. "Intention, History, and Artifact Concepts." Cognition 60: 1-29.

Stefano Borgo and Laure Vieu. 2009. "Artifacts in Formal Ontology." In Philosophy of Technology and Engineering Sciences, edited by Anthonie Meijers, 273-308. Amsterdam: Elsevier.

Robert Cummins. 1975. "Functional Analysis." The Journal of Philosophy 72: 741-765.

Stephen Davies. 1991. Definitions of Art. Ithaca: Cornell University Press.

George Dickie. 1984. The Art Circle: A Theory of Art. Evanston, Illinois: Chicago Spectrum Press.

George Dickie. 2004. “The New Institutional Theory of Art.” In Aesthetics and the Philosophy of Artthe Analytic Tradition, edited by Peter Lamarque and Stein Olsen, 47-54. Oxford: Blackwell.

Randall R. Dipert. 1993. Artifacts, Art Works, and Agency. Philadelphia: Temple University Press.

Julian Dodd. 2007. Works of Music: An Essay in Ontology. Oxford: OUP.

Marcia Eaton. 1969. “Art, Artifacts, and Intentions.” American Philosophical Quarterly 6 (2): 165-169.

Crawford L. Elder. 2014. "Artifacts and Mind-Independence." In Artefact Kinds: Ontology and the Human-Made World, edited by Maarten Franssen, Peter Kroes, Thomas A. C. Reydon, and Pieter Vermaas, 27-43. New York: Springer.

Crawford L. Elder. 2007. "On the Place of Artifacts in Ontology." In Creations of the Mind, edited by Eric Margolis and Stephen Laurence, 33-51. Oxford: OUP. 
Simon Evnine. 2018. "The Anonymity of a Murmur: Internet Memes.” British Journal of Aesthetics 58 (3): 303-318.

Simon Evnine. 2016. Making Objects and Events: A Hylomorphic Theory of Artifacts, Actions, and Organisms. Oxford: OUP.

Simon Evnine. 2013. "Ready-Mades: Ontology and Aesthetics." British Journal of Aesthetics 53 (4): 407-423.

Maarten Franssen. 2006. "The Normativity of Artefacts." Studies in the History and Philosophy of Science 37: 42-57.

Maarten Franssen and Peter Kroes. 2014. "Artefact Kinds, Ontological Criteria and Forms of MindDependence." In Artefact Kinds: Ontology and the Human-Made World, edited by Maarten Franssen, Peter Kroes, Thomas A. C. Reydon, and Pieter Vermaas, 63-83. New York: Springer.

David Friedell. 2019. “Abstracta Are Causal” Philosophia https://doi.org/10.1007/s11406-01900073-9.

David Friedell. 2016. "Abstract Creationism and Authorial Intention.” Journal of Aesthetics and Art Criticism 74 (2): 129-137.

Berys Gaut. 2000. “'Art' as a Cluster Concept.” In Theories of Art Today, edited by Noël Carroll, 2544. Madison, WI: University of Wisconsin Press.

Jeffrey Goodman. 2020. "On Inadvertently Made Tables: a Brockean Theory of Concrete Artifacts" Acta Analytica https://doi.org/10.1007/s12136-020-00438-w.

James L. Gould. 2007. “Animal Artifacts.” In Creations of the Mind, edited by Eric Margolis and Stephen Laurence, 249-266. Oxford: OUP.

Darren Hudson Hick. 2019. "Using Things as Art.” Grazer Philosophische Studien 96: 56-80.

Risto Hilpinen. 2011. "Artifact”, The Stanford Encyclopedia of Philosophy

URL<http://plato.stanford.edu/archives/win2011/entries/artifact/>.

Risto Hilpinen. 1992. “On Artifacts and Works of Art.” Theoria 58: 58-82.

Wybo Houkes and Pieter Vermaas. 2014. "On What Is Made: Instruments, Products, and Natural Kinds of Artefacts." In Artefact Kinds: Ontology and the Human-Made World, edited by Maarten Franssen, Peter Kroes, Thomas A. C. Reydon, and Pieter Vermaas, 167-190. New York: Springer.

Nurbay Irmak. 2021. "Authorship and Creation." Journal of Aesthetics and Art Criticism 20: DOI: $10.1093 / \mathrm{jaac} / \mathrm{kpab} 004$. 
Nurbay Irmak. 2018. “An Ontology of Words.” Erkenntnis https://doi.org/10.1007/s10670-0180001-0.

Nurbay Irmak. 2020. "The Problem of Creation and Abstract Artifacts” Synthese https://doi.org/10.1007/s11229-020-02672-6.

Nurbay Irmak. 2012. "Software is an Abstract Artifact.” Grazer Philosophische Studien 86 (1): 55-72.

Gary Iseminger. 1973. “The Work of Art as Artifact.” British Journal of Aesthetics 13: 3-16.

Tim Juvshik. 2018. “Abstract Objects, Causal Efficacy, and Causal Exclusion.” Erkenntnis 83 (4): 805-827.

Tim Juvshik. 2021a. "Artifacts and Mind-Dependence." Synthese https://doi.org/10.1007/s11229021-03204-6.

Tim Juvshik. 2021b. "Function Essentialism about Artifacts." Philosophical Studies https://doi.org/10.1007/s11098-020-01594-w.

Tim Juvshik. 2020. "Relativity and the Causal Efficacy of Abstract Objects." American Philosophical Quarterly 57 (3): 269-282.

Muhammad Khalidi. 2016. “Mind-Dependent Kinds.” Journal of Social Ontology 2 (2): 223-246.

Daniel Z. Korman. 2015. Objects: Nothing Out of the Ordinary. Oxford: OUP.

Kathrin Koslicki. 2018. Form, Matter, Substance. Oxford: OUP.

Kathrin Koslicki. 2008. The Structure of Objects. Oxford: OUP.

Jerrold Levinson. 2007. "Artworks as Artifacts." In Creations of the Mind, edited by Eric Margolis and Stephen Laurence, 74-82. Oxford: OUP.

Jerrold Levinson. 1980. "What a Musical Work Is.” Journal of Philosophy 77 (1): 5-28.

David Lewis. 1999. “Extrinsic Properties.” In Papers in Metaphysics and Epistemology, 111-115.

Cambridge: CUP.

Dominic McIver Lopes. 2007. “Art Without 'Art'.” British Journal of Aesthetics 47 (1): 1-15.

E. J. Lowe. 2014. "How Real are Artefacts and Artefact Kinds?" In Artefact Kinds: Ontology and the Human-Made World, edited by Maarten Franssen, Peter Kroes, Thomas A. C. Reydon, and Pieter Vermaas ,17-26. New York: Springer.

David Macaulay. 1979. Motel of the Mysteries. New York: Houghton Mifflin.

Christy Mag Uidhir. 2013. Art and Art-Attempts. Oxford: OUP. 
Peter McLaughlin. 2001. What Functions Explain: Functional Explanation and Self-Reproducing Systems. Cambridge: Cambridge University Press.

Ruth Garrett Millikan. 1984. Language, Thought and Other Biological Categories. Cambridge, MA: MIT Press.

Steven Mithen. 2007. "Creations of Pre-Modern Human Minds: Stone Tool Manufacture and Use by Homo habilis, heidelbergensis, and neanderthalensis." In Creations of the Mind, edited by Eric Margolis and Stephen Laurence, 289-311. Oxford: OUP.

Irene Olivero. 2019. "Function Is Not Enough.” Grazer Philosophische Studien 96: 105-129.

Wendell H. Oswalt. 1976. An Anthropological Analysis of Food-Getting Technology. New York: John Wiley and Sons.

Glenn Parsons and Allen Carlson. 2008. Functional Beauty. Oxford: Clarendon Press.

Beth Preston. 2009. "Philosophical Theories of Artifact Function." In Philosophy of Technology and Engineering Sciences, edited by Anthonie Meijers, 213-233. Amsterdam: Elsevier.

Thomas A. C. Reydon. 2014. "Metaphysical and Epistemological Approaches to Developing a Theory of Artifact Kinds." In Artefact Kinds: Ontology and the Human-Made World, edited by Maarten Franssen, Peter Kroes, Thomas A. C. Reydon, and Pieter Vermaas, 125-144. New York: Springer.

Edward Sankowski. 1980. "Free Action, Social Institutions, and the Definition of 'Art'." Philosophical Studies 37: 67-79.

Marcel Scheele. 2006. "Function and Use of Technical Artefacts: Social Conditions of Function Ascription." Studies in History and Philosophy of Science 37: 23-37.

Douglas Schnurrenberger and Alan Bryan. 1985. "A Contribution to the Study of the Naturefact/Artifact Controversy.” In Stone Tool Analysis, edited by Mark G. Plew, James C. Woods, and Max G. Pavesic, 133-159. Albuquerque: University of New Mexico Press.

Marzia Soavi. 2009. "Realism and Artifact Kinds." In Functions in Biological and Artificial Worlds, edited by Ulrich Krohs and Peter Kroes, 185-202. Cambridge, MA: MIT Press.

Amie L. Thomasson. 2007. "Artifacts and Human Concepts." In Creations of the Mind, edited by Eric Margolis and Stephen Laurence, 52-73. Oxford: OUP.

Amie L. Thomasson. 1999. Fiction and Metaphysics. Cambridge: Cambridge University Press.

Amie L. Thomasson. 2014. "Public Artifacts, Intentions, and Norms." In Artefact Kinds: Ontology and the Human-Made World, edited by Maarten Franssen, Peter Kroes, Thomas A. C. Reydon, and Pieter Vermaas, 45-62. New York: Springer. 
Amie L. Thomasson. 2003. "Realism and Human Kinds." Philosophy and Phenomenological Research 67 (3): 580-609.

Morris Weitz. 1956. "The Role of Theory in Aesthetics." Journal of Aesthetics and Art Criticism 15: $27-$ 35.

David Wiggins. 2001. Sameness and Substance Renewed. Cambridge: Cambridge University Press.

Michel Xhignesse. 2020. "Failures of Intention and Failed-Art." Canadian Journal of Philosophy 50 (7): 905-917.

Dean Zimmerman. 2002. "The Constitution of Persons by Bodies: A Critique of Lynne Rudder Baker's Theory of Material Constitution.” Philosophical Topics 30: 295-338. 